\title{
INTRASPECIFIC VARIABILITY IN NUCLEOLAR ORGANISER POSITION IN LACERTA (TIMON) LEPIDA
}

Mateo, Jose A ${ }^{\text {a }}$ Lopez-Jurado, Luis F. ${ }^{\text {b. }}$ Cano, Jesus ${ }^{c}$; Guillaume, Claude P. ${ }^{d}$

a CSIC, Estac Biol Donana, E-41080 Seville, Spain

b Univ Las Palmas Gran Canaria, Dept Biol, E-35016 Las Palmas Gran Canaria, Spain

c Univ Malaga, Dept Biol Celular \& Genet, E-29071 Malaga, Spain

d Univ Montpellier 2, EPHE, Lab Biogeog \& Ecol Vertebres, F-34095 Montpellier 05, France

\section{Abstract}

Discusses several studies on herpetology. Intraspecific variability in nucleolar organiser position in Lacerta (Timon) lepida; Habitat characteristics of the spectacled salamander Salamandrina terdigitata in southern Latium in Central Italy; Body temperatures of the monitor lizard Varanus tristis during the breeding season. 